\title{
House of cards: cultural taxonomy and the study of the European Upper Palaeolithic
}

Natasha Reynolds ${ }^{1, *} \&$ Felix Riede ${ }^{2}$

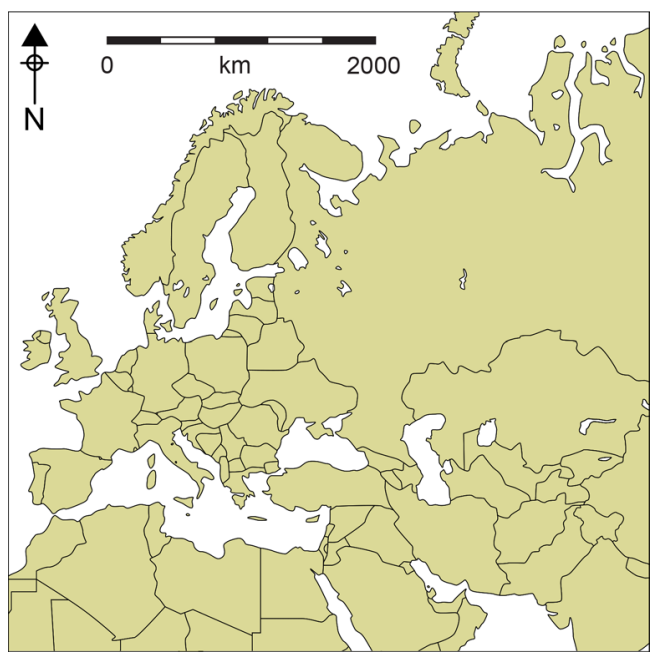

A fundamental element of Upper Palaeolithic archaeological practice is cultural taxonomythe definition and description of taxonomic units that group assemblages according to their material culture and geographic and chronological distributions. The derived taxonomies, such as Aurignacian, Gravettian and Magdalenian, are used as units of analysis in many research questions and interpretations. The evidential and theoretical bases defining these taxonomic units, however, are generally lacking. Here, the authors review the current state of Upper Palaeolithic cultural taxonomy and make recommendations for the long-term improvement of the situation.

Keywords: Europe, Upper Palaeolithic, cultural taxonomy, archaeological theory, systematics

\section{Introduction}

Cultural taxonomy is fundamental to Upper Palaeolithic archaeological practice. We define cultural taxonomy as the characterisation and description of taxonomic units (e.g. technocomplexes and archaeological cultures), bounded in space and time, grouping sites and assemblages. These units are deployed to organise our knowledge of the Upper Palaeolithic and they form the basis of much analysis.

The current system embraces a plethora of taxa, such as Aurignacian, Gravettian, Solutrean, Epigravettian, Magdalenian, Hamburgian and Ahrensburgian; these units may also

1 UMR 5199 PACEA, Université de Bordeaux, Bâtiment B8, Allée Geoffroy Saint Hilaire, CS 50023, PESSAC CEDEX 33615, France

2 Department of Archaeology and Heritage Studies, Aarhus University, Moesgård Allé 20, Højbjerg 8270, Denmark

* Author for correspondence (Email: natasha.reynolds@u-bordeaux.fr)

(C) Antiquity Publications Ltd, 2019. This is an Open Access article, distributed under the terms of the Creative Commons Attribution-NonCommercial-ShareAlike licence (http://creativecommons.org/licenses/by-nc-sa/4.0/), which permits non-commercial re-use, distribution, and reproduction in any medium, provided the same Creative Commons licence is included and the original work is properly cited. The written permission of Cambridge University Press must be obtained for commercial re-use.

ANTIQUITY 93371 (2019): 1350-1358 https://doi.org/10.15184/aqy.2019.49 
include sub-units, such as Early Aurignacian and Pavlovian. Upper Palaeolithic taxa are defined principally using lithic material, and are meant to describe more or less chronologically and geographically coherent groups of assemblages. The use of these units is fundamental to archaeological practice, yet we have numerous concerns regarding the shortcomings of the present cultural taxonomic system and its effects on Upper Palaeolithic research. These concerns are grounded in our experiences of the direct study of lithic assemblages, research history and cultural taxonomy (Reynolds 2014; Riede 2017). Indeed, much of what we write here is, we believe, widely understood among lithic specialists.

The present contribution has several aims. The problems with European Upper Palaeolithic cultural taxonomy need to be openly discussed in print. We want to encourage caution among researchers who use these terms, but who are not fully familiar with their epistemological bases. Finally, we seek to promote changes in the approaches of material culture specialists, in order to help address these problems over the long term.

\section{Contemporary cultural taxonomies}

The current set of Upper Palaeolithic cultural taxonomies has developed-largely unsystematically_over many decades, to structure the archaeological record (Clark 2009). The widespread application of the system originally developed for Aquitanian material has facilitated the recognition of broad-scale similarity among early and mid Upper Palaeolithic assemblages across Europe. The distribution of assemblages described as Aurignacian and Gravettian, for example, extends across the entire continent from Iberia to Russia (Teyssandier 2006; Noiret 2013; Dinnis et al. 2019). The situation is rather different for the late Upper Palaeolithic, with Epigravettian assemblages described in the east and south of Europe, and Badegoulian and Magdalenian assemblages in the west (Maier 2015; Naudinot et al. 2017).

Below these highest-level taxonomic units, there are many other smaller units in use. Aurignacian assemblages in Western Europe, for example, have been grouped into numerous phases (Bordes et al. 2011), and regionally and chronologically restricted Gravettian subunits (e.g. Pavlovian, Noaillian) are well established (Noiret 2013). In Eastern Europe, many pre-Last Glacial Maximum assemblages are not described as either Aurignacian or Gravettian, but rather are attributed to regionally specific taxonomic units (e.g. Streletskian and Gorodtsovian; Sinitsyn 2010). There are also multiple sub-units in use for Magdalenian assemblages (e.g. Langlais et al. 2016). For the post-Magdalenian Final Palaeolithic, often studied in connection with the Mesolithic, a multiplicity of taxonomic units is in use, including final Epigravettian, the Federmessergruppen, Azilian and Swiderian (Naudinot et al. 2017; Sauer \& Riede 2019).

\section{The shortcomings of the current system}

There is good reason to believe that our current cultural taxonomy does not provide an accurate reflection of variation in the archaeological record. The numerous inconsistencies in how taxonomic units are constructed and in the splitting and lumping

(C) Antiquity Publications Ltd, 2019 
of assemblages—-particularly for the post-Gravettian period — should give us pause. Consequently, any operationalisations or interpretations relying on such units should be viewed with due caution. The distinction, for example, between Epigravettian assemblages in Eastern/Central Europe and Badegoulian/Magdalenian assemblages in Western/Central Europe is, in fact, highly questionable (Maier 2015: 236-37; Naudinot et al. 2017). Furthermore, as suggested by the term 'Epigravettian', there is typically held to be far more similarity between Gravettian and Epigravettian assemblages than between Aurignacian and Gravettian assemblages. This is often interpreted as reflecting population continuity (Anghelinu et al. 2012; Perlès 2013; Kaminská 2016). The robustness of the multiplicity of units describing the Final Palaeolithic record is also debatable. In Central Europe, some units appear to reflect differing research histories more than empirical variation between assemblages (Sauer \& Riede 2019).

Many of these problems can be explained by historical factors, including political and linguistic considerations (Tomášková 2003; Roberts \& Vander Linden 2011). The quantity and quality of archaeological work that has been carried out across Europe also varies widely, and the biased distribution of known sites affects our understanding of material variation within the archaeological record. Problems of chronology and time averaging for earlier periods may also help to explain the fact that our late Upper and Final Palaeolithic cultural taxonomy appears relatively complex.

Previous work on archaeological systematics and the theory of cultural taxonomy is highly relevant here. Archaeology has a rich history of studying the epistemology and theory of cultural taxonomic units (e.g. Clarke 1968; Dunnell 1971; Jones 1997; O’Brien \& Lyman 2002; Riede 2011). It is striking, however, that recent work on the European Upper Palaeolithic seems, with few exceptions, to show very little engagement with this literature, preferring either to use existing taxonomic units uncritically, or to take a largely ad hoc approach to their revision and creation. This absence of engagement perhaps explains a fundamental theoretical shortcoming in Upper Palaeolithic cultural taxonomy: it is unclear what our discipline believes cultural taxonomy is for. That is not to say that it has no current uses; it clearly does. Taxonomy is used to organise the record, to structure research and frequently as the basis of analysis, as well as for scientific and popular communication. There is, however, no strong consensus—nor much recent published discussion—on the epistemological aims of cultural taxonomy.

The results of a cultural taxonomy whose purpose is to describe variation in material culture might look quite different to those of a cultural taxonomy whose purpose is to describe past population structures. A cultural taxonomy that aims to identify and differentiate instances of convergence in cultural traditions will produce different results from one that does not. A cultural taxonomy that aims to include information deriving from faunal assemblages, personal ornaments or funerary activity will reach different conclusions from one that considers evidence from lithic assemblages alone. Taxonomies based on variation in finished tool forms will differ from taxonomies based on technological characteristics. Cultural taxonomies that expect a hierarchical structure, or seek to reflect the historical usage of terms, will produce different outcomes from those that do not.

At present, Upper Palaeolithic taxonomic units are not equivalent in their epistemological aims, the amount of variation that they subsume, the degree of idiosyncrasy that they exhibit,

(C) Antiquity Publications Ltd, 2019 
or the amount of time or geographic space that they encompass. This creates serious problems when using these units as the basis for analysis or interpretation. Moreover, taxonomically classified Palaeolithic archaeological cultures offer the impression of interpretative familiarity: they imply some form of self-conscious identity, although the degree to which such named units are intended to match ethnographically or linguistically recognised groupings is not usually acknowledged. Unless we reach formal consensus on the aims of cultural taxonomy, its methods and theoretical framework, these difficulties will persist.

\section{House of cards: the effects of this on research}

The consequences of this situation for research are significant. Many archaeological interpretations rely on cultural taxonomy to provide units of analysis. These interpretations, however, rest on a chain of reasoning akin to a house of cards (Figure 1).

Cultural taxonomic problems present an obstacle to understanding and interpreting the Upper Palaeolithic record. Some of the most acute potential problems arise when, as commonly occurs, a small number of assemblages are considered to be representative of an entire taxonomic unit and are then used to draw conclusions regarding that unit as a whole. In other cases, the number of taxonomic units in a part of the record associated with a given period or area is inappropriately used as a measure of past cultural diversity. Other potential issues arise

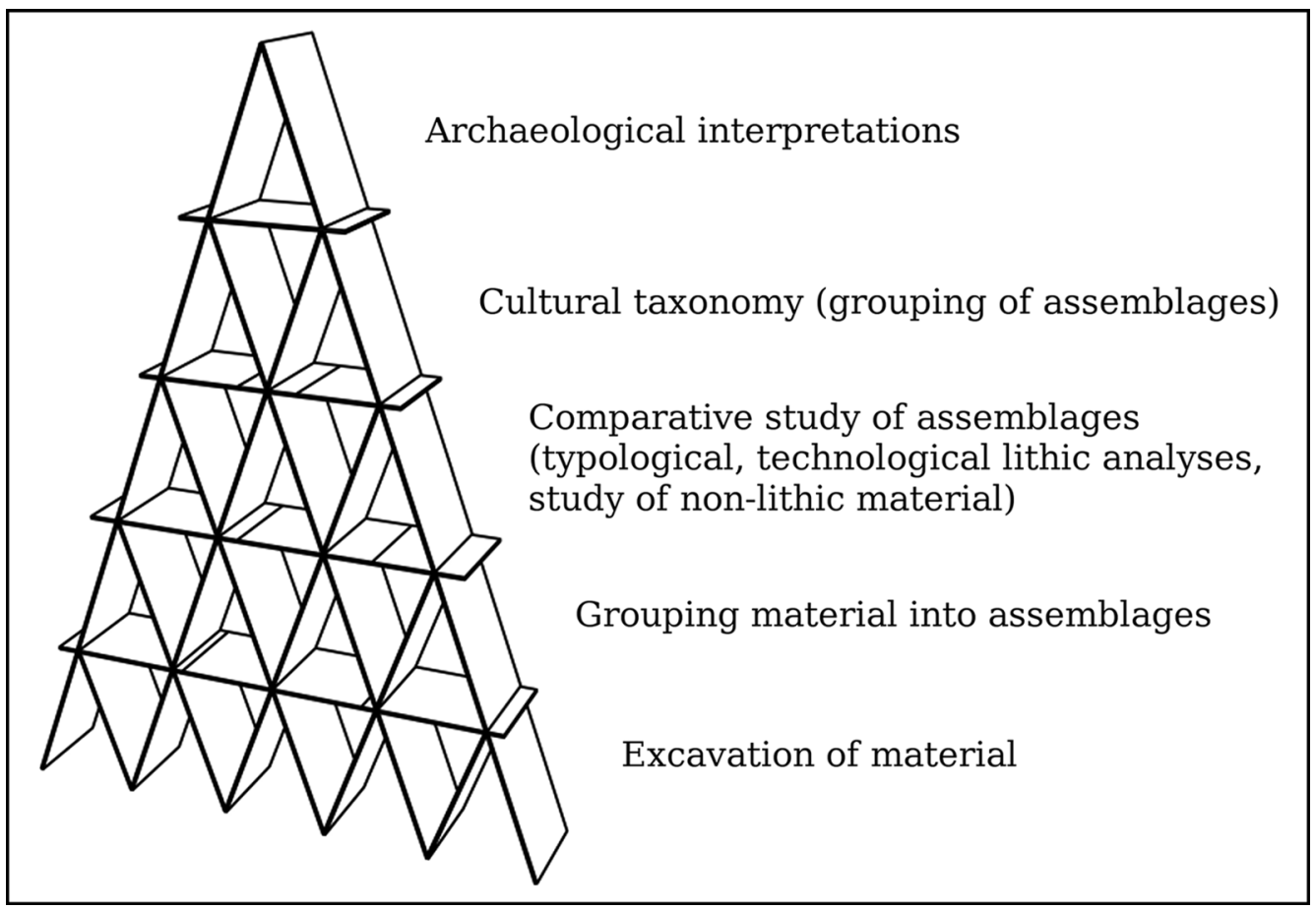

Figure 1. The house of cards of Upper Palaeolithic archaeological interpretation (figure by Natasha Reynolds and Felix Riede, based on an image by Lluisa Iborra licensed under CC BY 3.0; the figure is available at https:/ldoi.orgl 10.6084/m9.figshare.8293784 and is licensed under CC BY 4.0). 
where taxonomic units are used as proxies for past populations or even ethnic units. Shea (2014) and Neeley and Barton (1994) have discussed such problems for the Levantine Middle Palaeolithic and Epipalaeolithic. Although the situation for the European Upper Palaeolithic is generally different, there are commonalities.

While the issues described here are not new, the necessity of addressing them is increasingly pressing. Improved communication and cooperative international research mean that, for many of us whose research directly involves material culture, these taxonomic problems and their common roots are now so obvious that the situation is becoming untenable. These problems are also brought into focus by recent findings from ancient DNA studies, which describe several large genetic turnovers and periods of continuity in European populations that are poorly reflected in the current cultural taxonomic framework (Fu et al. 2016; Posth et al. 2016). Although we do not expect genetic and archaeological data to mirror each other exactly, these strong differences are surprising, and a robust understanding of cultural taxonomy is necessary in order to evaluate their significance (cf. Riede et al. 2019). Finally, specialists without a background in cultural taxonomy or material culture studies are making more frequent use of the archaeological record. This particularly concerns colleagues in archaeological science and allied disciplines, such as genetics, palaeoanthropology and palaeoclimatology. If these specialists are not fully aware of the complexities of cultural taxonomy, the robustness of their research questions and interpretations may be compromised.

\section{The remedies}

Our first recommendation is addressed to our colleagues who do not work directly on the construction and revision of cultural taxonomies. To these individuals, we advise that circumspection be used when working with Upper Palaeolithic taxonomic units, and preferably that research is carried out in collaboration with archaeologists who can offer a critical analysis of these units. In particular, we urge colleagues not to assume the validity of named taxonomic units, especially for the late Upper and Final Palaeolithic.

Our second set of recommendations is directed at our colleagues working on the study of material culture variation in the archaeological record. To address the fundamental problems with current cultural taxonomy, we need to reconsider such variation from first principles: we need better ways of describing and quantifying assemblage variation that go beyond ideal types and central tendencies. Examinations of inter- and intra-assemblage variation in the archaeological record as a whole are a sine qua non for robust cultural taxonomy. We also require explicit theoretical and methodological work on why and how to group assemblages.

Many problems with current cultural taxonomy are caused by difficulties in conducting comparative research on diverse collections. There are essentially two ways of conducting comparative research: direct first-hand study; and comparison based on published interpretations, descriptions and illustrations (Figure 2). The first is the best way of gaining a detailed understanding of assemblages, although it is also time-consuming and often expensive. The latter remains tremendously important, despite its well-recognised shortcomings. 


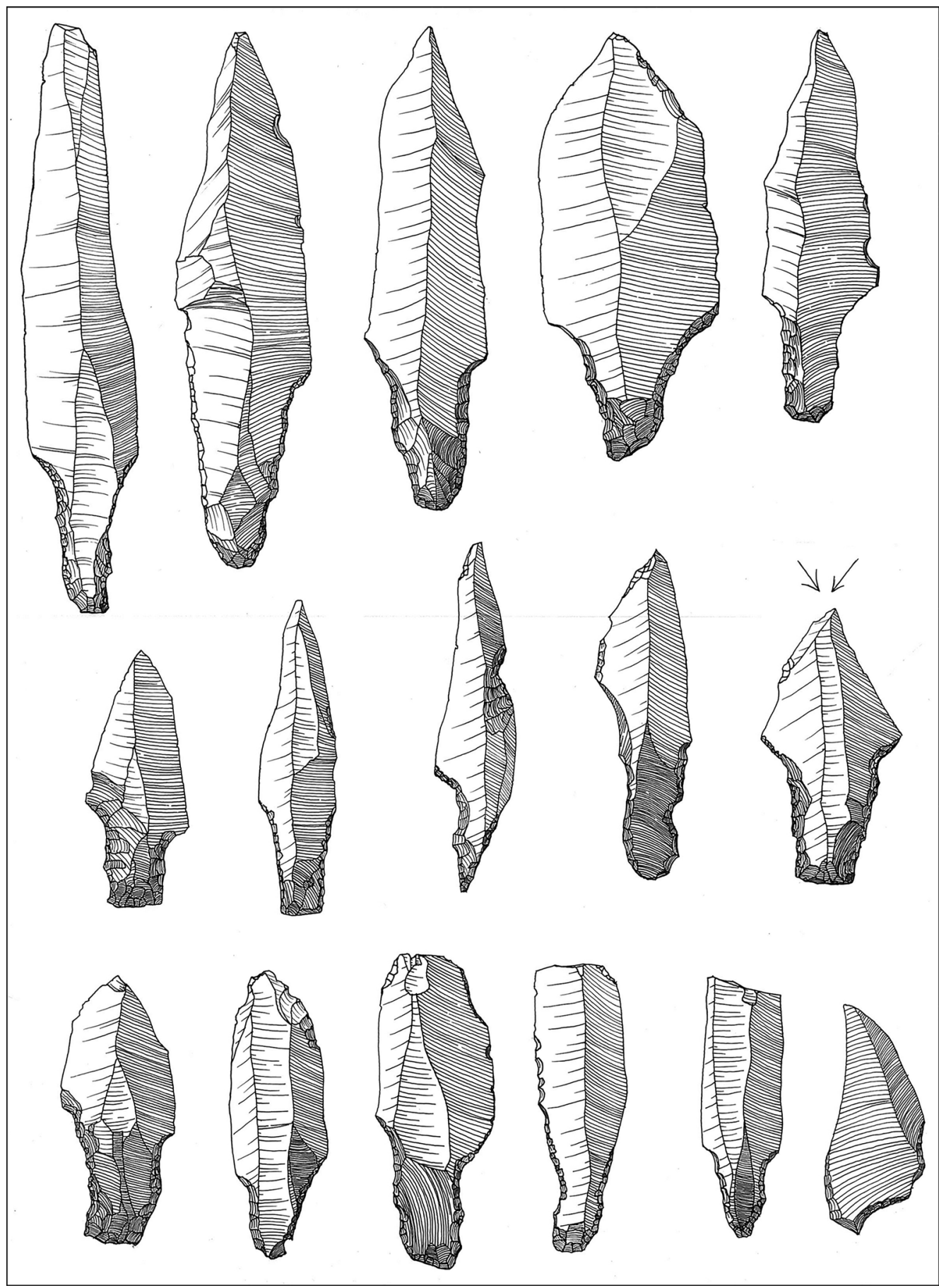

Figure 2. Morphological variability in one assemblage alone: the large tanged points from the Bromme site on Zealand, eastern Denmark (Final Palaeolithic). These objects were arbitrarily selected by the excavator for drawing and to be representative of the total variability of the eponymous archaeological culture. Subsequent publications on the Bromme Culture commonly show even less of the shape variability of this supposedly diagnostic artefact class. Redrawn from Mathiessen (1946: fig. 6).

(C) Antiquity Publications Ltd, 2019 
It is, however, not straightforward to compare the final interpretations of published lithic studies. Even if we disregard problems of inter-observer variability, there are strong differences between the various schools of lithic analysis. Contrasts can be made between approaches that emphasise technology or typology, chaîne opératoire studies, reduction sequences or attribute analyses, and those that are more or less quantitative or qualitative (Shott 2003; Tomášková 2005; Scerri et al. 2016; Hussain 2018).

In order to conduct large-scale comparative work, we are reliant on the work of other people. But we cannot simply and unquestioningly employ their final interpretations of particular assemblages: we need to be able to compare data directly. At present, however, there is extraordinarily little published data on Upper Palaeolithic lithic assemblages that is suitable for such re-use. Although summary data may be provided, the full datasets used for analyses are very rarely published. We urgently need improved sharing of data within the framework of an open archaeology (Wilson \& Edwards 2015; Marwick 2017).

Data alone, however, have little value without a full description of how they were produced. We need more openness about how we study lithic assemblages, our choices in recording and our classification methods. With full publication of methods, data and metadata, we will, at last, begin to amass a corpus of re-usable data. As this continues, some standardisation of methods and data structures should emerge; at the very least, it will provide a clearer indication of variation in current practice. The greater availability of data will allow archaeologists to make more detailed comparisons of assemblages, and hence improve our cultural taxonomies. These shifts will require investment in data-sharing infrastructure along with further development of, for instance, 3D recording technologies. They will also demand computational expertise and training and consistent adherence to data-sharing principles. In any case, there is a widespread trend-increasingly enforced by funders, institutions and publisherstowards openness in research; archaeology needs to respond to this.

Both authors are endeavouring to produce shareable, re-usable data on lithic assemblages (e.g. Reynolds et al. 2019; Riede et al. 2019; Sauer \& Riede 2019). While there is some effort involved in achieving this, it is not excessive in the context of the total amount of work needed to bring a study to publication. Planning to produce open data from the outset of our studies has compelled us to think harder about our methods and research questions, and has helped us ultimately to do better research. At the same time, the authors differ quite strongly in how we envisage the possible cultural taxonomies of Upper Palaeolithic Europe, and we would argue for different theoretical and methodological approaches. Nonetheless, we jointly recognise the necessity of overhauling the current framework, which is shaped by contingent factors and lacks a satisfactory theoretical basis. Archaeology needs a cultural taxonomy that is robust, open, revisable and extensible. This, we believe, is the most critical problem currently facing Upper Palaeolithic research. It will be solved by a return to the material on which we base our taxonomies and interpretations, and by establishing an extensive corpus of re-usable data. By applying theoretically justified approaches to these data, we will be able to rebuild our house of cards — this time on strong foundations.

\section{Acknowledgements}

We are grateful to the anonymous reviewers for their constructive comments that were helpful in improving the manuscript. N.R. thanks the Fondation Fyssen and the European Union's Horizon 2020 research and innovation

(C) Antiquity Publications Ltd, 2019 
programme under Marie Skłodowska-Curie grant agreement 747400; F.R. thanks the Independent Research Fund Denmark for grant \#6107-00059B and the European Research Council (Consolidator Grant agreement 817564 under the Horizon 2020 research and innovation programme).

\section{References}

Anghelinu, M., L. NițĂ \& L. Steguweit. 2012. Not that original after all: the chrono-cultural framework of the Upper Paleolithic on the Bistriţa Valley (northeastern Romania). Arheologia Moldovei 35: 7-46.

Bordes, J.-G., F. Bachellerie, F. LE Brun-Ricalens \& A. Michel. 2011. Towards a new 'transition'. New data concerning the lithic industries from the beginning of the Upper Palaeolithic in southwestern France, in A.P. Derevianko \& M.V. Shunkov (ed.) Characteristic features of the Middle to Upper Palaeolithic transition in Eurasia: 11-23. Novosibirsk: IAE SB RAS.

Clarke, D.L. 1968. Analytical archaeology $\left(2^{\text {nd }}\right.$ edition). London: Methuen.

Clark, G.A. 2009. Accidents of history: conceptual frameworks in paleoarchaeology, in M. Camps \& P. Chauhan (ed.) Sourcebook of Paleolithic transitions: 19-41. New York: Springer.

Dinnis, R., A. Bessudnov, N. Reynolds, T. Devièse, A. Pate, M. Sablin, A. Sinitsyn \& T. Higham. 2019. New data for the early Upper Palaeolithic of Kostenki (Russia). Journal of Human Evolution 127: 21-40. https://doi.org/10.1016/j.jhevol.2018.11.012

Dunnell, R.C. 1971. Systematics in prehistory. New York: Free Press.

Fu, Q. et al. 2016. The genetic history of ice age Europe. Nature 534: 200-205. https://doi.org/10.1038/nature17993

Hussain, S.T. 2018. The French-Anglophone divide in lithic research: a plea for pluralism in Palaeolithic archaeology. Unpublished PhD dissertation, Leiden University.

JoNes, S. 1997. The archaeology of ethnicity: constructing identities in the past and present. London: Routledge.

KaminsKá, L'. 2016. Gravettian and Epigravettian lithics in Slovakia. Quaternary International 406 (A): 144-65.

Langlais, M., A. Sécher, S. Caux, V. Delvigne, L. Gourc, C. Normand \& M.S. de la Torre. 2016. Lithic tool kits: a metronome of the evolution of the Magdalenian in south-west
France (19 000-14 $000 \mathrm{cal} \mathrm{BP).} \mathrm{Quaternary}$ International 414: 92-107. https://doi.org/10.1016/j.quaint.2015.09.069

MaIer, A. 2015. The Central European Magdalenian: regional diversity and internal variability. Dordrecht: Springer. https://doi.org/10.1007/978-94-017-7206-8

Marwick, B. 2017. Computational reproducibility in archaeological research: basic principles and a case study of their implementation. Journal of Archaeological Method and Theory 24: 424-50. https://doi.org/10.1007/s10816-015-9272-9

Mathiessen, T. 1946. En senglacial Boplads ved Bromme. Aarbøger for nordisk Oldkyndighed og Historie 1946: 121-97.

Naudinot, N., A. Tomasso, E. Messager, W. Finsinger, P. Ruffaldi \& M. Langlais. 2017. Between Atlantic and Mediterranean: changes in technology during the Late Glacial in Western Europe and the climate hypothesis. Quaternary International 428(B): 33-49.

Neeley, M.P. \& C.M. Barton. 1994. A new approach to interpreting late Pleistocene microlith industries in southwest Asia. Antiquity 68: 275-88. https://doi.org/10.1017/S0003598X00046585

Noiret, P. 2013. De quoi Gravettien est-il le nom ?, in M. Otte (ed.) Les Gravettiens: 29-64. Paris: Éditions Errance.

O'Brien, M.J. \& R.L. Lyman. 2002. The epistemological nature of archaeological units. Anthropological Theory 2: 37-56. https://doi.org/10.1177/1463499602002001287

PerLès, C. 2013. Tempi of change: when soloists don't play together. Arrhythmia in 'continuous' change. Journal of Archaeological Method and Theory 20: 281-99. https://doi.org/10.1007/s10816-012-9164-1

Posth, C., G. Renaud, A. Mittnik, D.G. Drucker, H. Rougier, C. Cupillard, F. Valentin, C. Thevenet, A. Furtwängler \& C. WIssing. 2016. Pleistocene mitochondrial genomes suggest a single major dispersal of non-Africans and a Late Glacial population turnover in Europe. Current Biology 26: 827-33. https://doi.org/10.1016/j.cub.2016.01.037

Reynolds, N. 2014. The mid Upper Palaeolithic of European Russia: chronology, culture history and

(C) Antiquity Publications Ltd, 2019 
context. A study of five Gravettian backed lithic assemblages. Unpublished $\mathrm{PhD}$ dissertation, University of Oxford.

Reynolds, N., M. Germonpré, A.A. Bessudnov \& M.V. SABLIN. 2019. The Late Gravettian site of Kostënki 21 Layer III, Russia: a chronocultural reassessment based on a new interpretation of the significance of intra-site spatial patterning. Journal of Paleolithic Archaeology 2: 160-210. https://doi.org/10.1007/s41982-018-0018-6

Riede, F. 2011. Steps towards operationalizing an evolutionary archaeological definition of culture, in B.W. Roberts \& M. Vander Linden (ed.) Investigating archaeological cultures: material culture, variability, and transmission: 245-70. New York: Springer. https://doi.org/10.1007/978-1-4419-6970-5_13

- 2017. The 'Bromme problem'-notes on understanding the Federmessergruppen and Bromme Culture occupation in Southern Scandinavia during the Allerød and early Younger Dryas chronozones, in M. Sørensen \& K.B. Pedersen (ed.) Problems in Palaeolithic and Mesolithic research: 61-85. Copenhagen:

University of Copenhagen \& Museum of Southeast Denmark.

Riede, F., C. Hoggard \& S. Shennan. 2019.

Reconciling material cultures in archaeology with genetic data requires robust cultural evolutionary taxonomies. Palgrave Communications 5(55). https://doi.org/10.1057/s41599-019-0260-7

Roberts, B.W. \& M.V. VANDER Linden. 2011. Investigating archaeological cultures: material culture, variability, and transmission, in B.W. Roberts \& M.V. Linden (ed.) Investigating archaeological cultures: material culture, variability, and transmission: 1-21. New York: Springer.

SAUER, F. \& F. Riede. 2019. A critical reassessment of cultural taxonomies in the Central European Late Palaeolithic. Journal of Archaeological Method and Theory 26: 155-184. https://doi.org/10.1007/s10816-018-9368-0
Scerri, E.M., B. Gravina, J. Blinkhorn \& A. Delagnes. 2016. Can lithic attribute analyses identify discrete reduction trajectories? A quantitative study using refitted lithic sets. Journal of Archaeological Method and Theory 23: 669-91. https://doi.org/10.1007/s10816-015-9255-x

ShEA, J.J. 2014. Sink the Mousterian? Named stone tool industries (NASTIES) as obstacles to investigating hominin evolutionary relationships in the later Middle Paleolithic Levant. Quaternary International 350: 169-79. https://doi.org/10.1016/j.quaint.2014.01.024

Sнотт, M.J. 2003. Chaîne opératoire and reduction sequence. Lithic Technology 28: 95-105. https://doi.org/10.1080/01977261.2003. 11721005

Sinitsyn, A.A. 2010. The early Upper Palaeolithic of Kostenki: chronology, taxonomy, and cultural affiliation, in C. Neugebauer-Maresch \& L.R. Owen (ed.) New aspects of the Central and Eastern European Upper Palaeolithic-methods, chronology, technology and subsistence: 27-48. Vienna: Österreichischen Akademie der Wissenschaften.

Teyssandier, N. 2006. Questioning the first Aurignacian: mono or multi-cultural phenomenon during the formation of the Upper Paleolithic in Central Europe and the Balkans. Anthropologie 44: 9-29.

TomÁšKovÁ, S. 2003. Nationalism, local histories and the making of data in archaeology. Journal of the Royal Anthropological Institute 9: 485-507. https://doi.org/10.1111/1467-9655.00160

-2005 . What is a burin? Typology, technology and interregional comparison. Journal of Archaeological Method and Theory 12: 79-115. https://doi.org/10.1007/s10816-005-5666-4

Wilson, A.T. \& B. Edwards. 2015. Open source archaeology: ethics and practice. Warsaw \& Berlin: De Gruyter Open. https://doi.org/10.1515/9783110440171

Received: 19 December 2018; Revised: 19 March 2019; Accepted: 26 March 2019

(C) Antiquity Publications Ltd, 2019 